\title{
Traços Identitários da Enfermeira-Gerente em Hospitais Privados de Belo Horizonte, Brasil
}

\section{The Nurse Manager's Identity Features in Private Hospitals of Belo Horizonte, Brazil}

Maria José Menezes Brito

Enfermeira. Doutora em Administração. Professora Adjunta - Departamento de Enfermagem Aplicada da Universidade Federal de Minas Gerais.

Endereço: Rua Professor José Renault, 277, apto 503, Bairro São Bento, CEP 30350-760, Belo Horizonte, MG, Brasil.

E-mail: brito®enf.ufmg.br

\section{Maristela Oliveira Lara}

Enfermeira. Mestranda em Enfermagem. Enfermeira do PSF do Município de Diamantina/MG.

Endereço: Rua Professor Gabriel Mandacaru, 121, apto 204, Bairro Bom Jesus, CEP 39100-000, Diamantina, MG, Brasil.

E-mail: maryslaraळhotmail.com

\section{Elisângela Guimarães Soares}

Enfermeira. Mestranda em Enfermagem. Docente do Curso de Enfermagem do Centro Universitário do Leste de Minas Gerais UNILESTEMG/UBEC.

Endereço: Rua Ambar, 80, Bairro Iguaçu, CEP 35165-019, Ipatinga, MG, Brasil.

E-mail: lisaguimaso®yahoo.com.br

\section{Marília Alves}

Enfermeira. Doutora em Enfermagem pela Escola de Enfermagem da USP. Professora da Escola de Enfermagem da Universidade Federal de Minas Gerais.

Endereço: Rua Teixeira de Freitas, 140/302, Santo Antônio, CEP 30350-180, Belo Horizonte, MG, Brasil.

E-mail: marilixळenf.ufmg.br

\section{Marlene Catarina de Oliveira Lopes Melo}

Jornalista. Doutora em Administração. Diretora Acadêmica da Faculdade Novos Horizontes. Professora Titular aposentada da Universidade Federal de Minas Gerais.

Endereço: Rua Alvarenga, 1270, Lourdes, CEP 30180-120, Belo Horizonte, MG, Brasil.

E-mail: lenemeloळunihorizontes.br

\section{Resumo}

Com o propósito de compreender aspectos subjetivos do trabalho da enfermeira-gerente, buscou-se, por meio deste estudo, analisar os traços identitários da enfermeira-gerente no contexto de instituições hospitalares a partir do questionamento fundamentado na apresentação que os sujeitos fazem de si mesmos. Trata-se de um estudo de caso, com abordagem qualitativa, do qual participaram nove enfermeiras-gerente que atuam em quatro instituições hospitalares privadas de médio e grande porte, no município de Belo Horizonte. Os traços identitários foram organizados de acordo com os planos profissional, organizacional e individual, os quais abrangem: preservação e reforço de identidade social da enfermeira, a trajetória profissional como uma evolução da prática da assistência para o exercício da gerência, valorização da experiência prática e permanência em atividades ligadas à prestação da assistência direta ao paciente; identificação com a organização; e questões relativas à vida privada e autoimagem positiva expressa pelas gerentes. 0 estudo permitiu a identificação de traços marcantes de um grupo profissional específico, evidenciando a influência das questões de gênero, das relações de poder e da cultura na identidade social dos sujeitos pesquisados.

Palavras-chave: Enfermeira-gerente; Traços identitários; Hospitais privados. 


\section{Abstract}

Aiming to understand subjective aspects of the work of nurse managers, this study analyzed their identity features in the context of hospital institutions. These were obtained through a questioning based on the introduction that the subjects make of themselves. It is a case study carried out according to the qualitative approach, in which nine nurse managers participated. They worked at four large- and medium-sized private hospitals in the city of Belo Horizonte. The identity features were organized in accordance with the professional, institutional and individual planes, which encompass: the preservation and reinforcement of the nurse's social identity, professional trajectory as a natural evolution from assistance practices to management practices, practical experience valuation and permanence in activities related to the provision of direct assistance to the patient; identification with the organization; and questions concerning the private life and positive self-image expressed by the nurses. The study allowed the identification of outstanding features of a specific professional group, revealing influences of gender questions, of power relations and of culture on the social identity of the researched subjects.

Keywords: Nurse Manager; Identity Features; Private Hospitals.

\section{Introdução}

Os atuais modelos de gestão, marcados principalmente pela descentralização administrativa, pela criação de equipes semi-autônomas, pela participação e ênfase no trabalho em equipe, têm apontado para a necessidade de adoção de métodos e estratégias que permitam a compreensão dos processos e contextos administrativos, nos quais os diferentes atores sociais encontram-se inseridos. A compreensão do papel da enfermeira-gerente a partir de seus traços identitários permite estabelecer uma análise que transcenda os tradicionais arquétipos que historicamente influenciaram a imagem social da enfermeira e sua inserção nos diferentes espaços profissionais.

No setor hospitalar, os novos modelos de gestão têm exigido uma nova postura por parte dos gestores e, portanto, o desenvolvimento de novas competências que contribuam para a ampliação da visão da organização, bem como para o reconhecimento das potencialidades dos profissionais que integram a equipe de saúde. Assim, observa-se a necessidade eminente de profissionalização da gerência, sobretudo na área da saúde, apontando, segundo Ciampa (2001); Jacques (2001), para uma configuração identitária em metamorfose, influenciada por questões mais abrangentes e complexas, tais como as relações de poder, gênero e a cultura que permeiam a organização hospitalar.

Partindo dessas premissas, o presente estudo busca analisar os traços identitários de enfermeiras em cargos de gerência em instituições hospitalares de médio e grande porte, que passaram ou vem passando por mudanças estruturais, gerenciais e processuais, tendo em vista as particularidades que marcam o universo da mulher-enfermeira-gerente nas esferas do trabalho e do espaço doméstico. Essas mudanças correspondem à criação de unidades funcionais autônomas ou semi-autônomas e auto-suficientes, diminuição dos níveis hierárquicos, processo de comunicação mais fluido, redução dos níveis decisórios e gestão participativa com co-responsabilização dos profissionais pelos resultados dos serviços prestados. 


\section{Metodologia}

Considerando-se as singularidades que povoam o universo de trabalho da enfermeira-gerente, optou-se, neste estudo, pela adoção da abordagem qualitativa, uma vez que a mesma apresenta maior possibilidade de responder as inquietações ligadas à dinâmica identitária da enfermeira no exercício da função gerencial. A eleição desse modo de acesso à realidade pressupõe a presença do sujeito na produção do conhecimento, abortando-se a lógica da produção de verdades como algo absoluto.

O estudo foi realizado em quatro hospitais privados de grande e médio porte de Belo Horizonte, no período de setembro a dezembro de 2003. Os sujeitos da investigação foram nove enfermeiras em cargos de gerência. Foi utilizada a seguinte questão norteadora: "Você poderia se apresentar para mim? Quem é a (nome da entrevistada)?". A coleta de dados foi feita em horário e local de trabalho das enfermeiras e as respostas obtidas foram gravadas após consentimento e exposição dos objetivos e finalidades do estudo e mediante aprovação do comitê de ética e pesquisa da UFMG. Os critérios estabelecidos para a seleção dos sujeitos da pesquisa foram: enfermeiras que ocupassem cargos gerenciais nos níveis intermediário (supervisora de unidade) ou estratégico da organização (diretoria).

Foi feito um estudo de caso (Yin, 2001), por meio do qual se buscou conhecer os traços identitários que caracterizam o grupo de enfermeiras-gerente nos hospitais eleitos como campo de estudo, tendo-se como pano de fundo as mudanças no contexto hospitalar. Para tanto, foram evidenciados aspectos subjetivos da vivência profissional das enfermeiras-gerente, como as relações de poder e de gênero envolvidas na dinâmica hospitalar e alguns traços culturais que caracterizam esse tipo de organização.

Na fase de preparação, as entrevistas foram transcritas na íntegra, segundo o roteiro de perguntas, englobando, além das entrevistas, o conjunto de observações obtidas no momento da sua realização. Após a transcrição das fitas, procedeu-se à releitura do material e à organização dos relatos em determinada ordem, pressupondo um início de classificação e organização dos dados de observação.
As fases consecutivas foram realizadas com vistas a atender à orientação de alguns autores como Bardin (1977), Melo (2002, 2003) e Turato (2003), no sentido de alcançar a categorização temática, a qual consistiu de dois momentos distintos: no primeiro momento, foram feitas repetidas leituras das entrevistas em sua totalidade; no segundo, foram extraídos os temas relevantes que emergiram dos discursos das entrevistadas.

A classificação dos dados possibilitou a apreensão das estruturas de relevância dos atores sociais, bem como as idéias centrais transmitidas. Em seguida, procedeu-se à constituição de um “corpus" de comunicações, as quais deram origem às categorias empíricas centrais. Na análise final dos dados, foram identificados os traços identitários que marcam o grupo de enfermeiras-gerente, no contexto dos novos modelos de gestão dos hospitais privados de grande e médio porte pesquisados.

\section{A Identidade: algumas considerações}

A natureza social, histórica, e, portanto, dinâmica da identidade é consenso entre os estudiosos (Hall, 1999; Caldas e Wood Júnior, 1997; Nkomo e Cox Jr., 1999; Castells, 200o). Nessa vertente de pensamento, Hall (1999), entre outros autores, defende a idéia de que a identidade não é fixa ou estável, mas, ao contrário, histórica e socialmente construída e sujeita a transformações. Portanto, não é inata e deve ser pensada nos níveis individual, grupal / intergrupal, organizacional e social (Nkomo e Cox Jr., 1999, p. 349).

De acordo com Tajfel (1978), no plano individual, a identidade emana do sentido atribuído pelo indivíduo à sua interação com grupos socialmente diversos no decorrer de sua trajetória de vida, e "o significado específico de cada um desses grupos de referência varia" conforme "a importância relativa das experiências de interação para a construção ou afirmação da auto-percepção" (p. 5o).

$\mathrm{Na}$ análise da identidade social, destaca os sentimentos de pertença e atos de atribuição como aqueles que visam a definir a identidade para o outro. Por outro lado, as ações que exprimem a "identidade para si" são denominadas "atos de pertencimento". Importa

1 Original: actos de pertença. 
salientar que não há necessariamente correspondência entre a identidade singular de uma determinada pessoa, com a sua história de vida, e as identidades atribuídas pelo outro, quer se trate das identidades numéricas ou genéricas. Importa esclarecer que as identidades numéricas definem a pessoa como ser único, e correspondem ao estado civil, códigos de identificação e números de ordem. Já as identidades genéricas permitem a classificação das pessoas como membros de um grupo, de uma categoria ou de uma classe (Dubar, 1997, p. 106).

O autor acrescenta que as trajetórias identitárias podem ser marcadas por dois eventos, quais sejam: a "continuidade inter e intrageracional" ou "rupturas" de naturezas diversas, as quais implicam a retomada de identidades anteriormente construídas. É importante salientar que as escolhas no campo educacional/profissional constituem, de uma forma ou de outra, uma antecipação do futuro estatuto social do indivíduo, ou seja, a opção por determinada especialidade ou área de atuação constitui importante elemento da identidade virtual.

Contudo, o mais importante desafio identitário dos indivíduos da geração de crise, acrescenta Dubar (1997), consiste no confronto com o mercado de trabalho, o qual assume diferentes formas e significados conforme o país, nível escolar e origem social. Segundo o autor, algumas condições históricas particulares têm marcado a referida geração. Dentre elas destacam-se a alta taxa de desemprego, afetando, de forma diferenciada, os trabalhadores segundo os países, níveis escolares, origens sociais e sexo; o rápido processo de modernização tecnológica e de mudanças organizacionais nos diferentes setores; o prolongamento da transição entre a saída da escola e o acesso a um emprego que assegure alguma estabilidade.

Nessa ótica, a "primeira identidade profissional para si” (p. 113) não é passível de ser considerada definitiva, estando, portanto, susceptível a sucessivos ajustes, uma vez que confronta, diretamente, com as mudanças tecnológicas, organizacionais e de gestão do emprego nas diferentes empresas.

A respeito da análise da construção da identidade social, além de se considerar as esferas do trabalho, do emprego e da formação, bem como do processo biográfico, há que se levar em consideração o processo identitário relacional. Esse processo diz respeito ao "reconhecimento, 'num dado momento e no seio de um espaço determinado' de legitimação, das identidades associadas aos saberes, competências e imagens de si propostas e expressas pelos indivíduos nos sistemas de ação" (Dubar, 1997, p. 118).

Dessa forma, são evidenciadas as relações de trabalho, nas quais o indivíduo participa de atividades coletivas, no âmbito da organização e intervêm, de uma ou outra forma, no jogo de atores. Tal perspectiva de identidade remete à definição de identidade de Sainsaulieu (1985), ou seja, a forma como os diferentes grupos, no trabalho, se identificam com seus pares, com os chefes e com outros grupos. "A identidade no trabalho baseia-se em representações coletivas diferentes, que constroem atores no sistema social da empresa" (p. 9). Tal perspectiva situa a identidade no campo da "experiência relacional e social do poder" (p. 342). Assim, as relações de trabalho são o 'lugar' onde se experimenta "o confronto dos desejos de reconhecimento num contexto de acesso desigual, movediço e complexo", sendo a identidade, para o autor, mais do que um processo biográfico de construção do eu, mas um processo relacional de investimento do eu (p. 342).

\section{A Enfermeira e as Práticas de Gestão no Espaço Hospitalar}

Ao analisar as práticas cotidianas no setor hospitalar, observa-se a participação, cada vez mais expressiva, de enfermeiras em cargos gerenciais, tanto no setor público quanto no privado (Alves, 1996; Trevisan, 1988; Barros, 1994; Bocchi e Fávero, 1996; Cecílio, 1997; Brito, 1998, 2002; Alves e Brito, 2001). O envolvimento da enfermeira em atividades gerenciais não é um fato novo, haja vista a sua inserção na coordenação da equipe de Enfermagem e na realização de atividades burocráticas desde a institucionalização da profissão. As atribuições da enfermeira abrangem ainda a realização de atividades assistenciais de maior complexidade, sendo as demais atividades delegadas ao profissional de nível médio. Para tanto, alguns tipos ou padrões de distribuição de tarefas vêm sendo utilizados na prestação dos cuidados pela enfermeira em cargo de gerência, sendo os mesmos descritos por Kron e Gray (1994).

A participação da enfermeira na realização de atividades gerenciais e assistenciais representa, para muitas enfermeiras, uma situação geradora de confli- 
tos e de indefinição quanto aos seus papéis, dado que, em muitos casos, assume-se um vasto leque de atividades cuja priorização e conciliação tornam-se praticamente inviáveis. No tocante à indefinição de papéis e das verdadeiras atribuições da enfermeira, Waldow (1996, p. 122) evidencia a presença histórica, na Enfermagem, da perpetuação de sentimentos negativos, tais como a falta de orgulho e a baixa auto-estima, o que, do ponto de vista da autora, decorrem, em grande parte, da falta de uma identidade própria.

Atualmente, constata-se o efetivo envolvimento da enfermeira em atividades tipicamente gerenciais. Em estudo sobre sua participação em cargos gerenciais em hospitais de grande e médio porte da rede privada de Belo Horizonte, Brito e Melo (2001a) verificaram que dos 413 enfermeiros contratados pelos hospitais pesquisados, 209 assumiam funções gerenciais, enquanto 204 desenvolviam atividades ligadas à prestação do cuidado direto ao cliente. No entanto, em relação ao grupo de enfermeiras que afirmavam desenvolver atividades relativas à prestação do cuidado direto ao cliente, observou-se que grande parte daquelas atividades encontrava-se ligada a questões de cunho essencialmente administrativo.

Nessa ótica, é reforçada a tendência histórica de realização de práticas gerenciais pela enfermeira e, a despeito da marcante presença das referidas práticas no seu cotidiano de trabalho, percebe-se que atualmente a função gerencial vem sendo assumida por esse profissional de forma mais consciente, havendo maior clareza das suas reais atribuições e da realidade de trabalho a ser enfrentada no exercício da função.

Além disso, os dirigentes das organizações reconhecem que a participação da enfermeira em cargos de gerência decorre de seu bom nível de conhecimentos relativos à operacionalização da prestação do cuidado e à capacitação na área administrativa. Tal situação está diretamente ligada ao conteúdo programático dos cursos de graduação em Enfermagem e de cursos específicos e adicionais sobre gestão, e à habilidade pessoal de coordenar o trabalho dos membros da equipe multiprofissional e de relacionar-se com a clientela. No exercício da gerência, a enfermeira tem se posicionado como elemento central na intermediação das ordens médicas e da alta administração, repassando a ideologia institucional à equipe de trabalho.

Essa situação pode ser exemplificada com base na análise dos traços de identificação que têm ligado as enfermeiras gerentes à organização (laços psicológicos, afetivos, materiais-financeiros e ideológicos), quando se percebe que os laços ideológicos sobressaem-se sobre os demais e que as diretrizes e valores organizacionais são fortemente assimilados pelas gerentes, as quais assumem papel relevante na transmissão da ideologia institucional dos dirigentes aos demais funcionários do hospital (Brito e Melo, 2001b).

O exercício da função gerencial pela enfermeira, no contexto hospitalar, reveste-se de grande complexidade, detendo algumas particularidades que parecem interferir diretamente no seu exercício profissional, em seus relacionamentos e, portanto, na sua configuração identitária.

\section{Traços Identitários: nuances do universo feminino e do contexto de trabalho na configuração identitária da enfermeira-gerente}

As descrições das gerentes, sobre si próprias, permitiram identificar os traços identitários ligados aos planos grupal/profissional, organizacional e individual, conforme classificação de Nkomo e Cox Jr. (1999). Os traços identitários envolveram aspectos relacionados à preservação e reforço de identidade social da enfermeira, à trajetória profissional como uma evolução da prática assistência para a gerencial, à valorização da experiência prática e permanência em atividades ligadas à prestação da assistência direta ao paciente, à identificação com a organização, a questões relativas à vida privada e, finalmente, à auto-imagem positiva expressa pelas gerentes.

No plano grupal ou profissional identificou-se a preservação e reforço da identidade social da enfermeira. As gerentes identificam-se como enfermeiras e, a despeito de assumirem funções gerenciais, não abrem mão da prestação do cuidado direto ao paciente. Esse comportamento é destacado pelas gerentes que atuam em unidades fechadas (CTI e Bloco Cirúrgico), nas quais as práticas assistenciais estão mais presentes no seu cotidiano do que nas unidades abertas (Unidades de internação).

0 exercício da gerência foi considerado uma evolução da assistência e parte de uma trajetória profis- 
sional pópria do enfermeiro e sustenta-se na formação e experiências assistenciais prévias:

A minha questão profissional foi evoluindo para a questão administrativa. Eu sempre fui uma enfermeira assistencial e, de repente, as oportunidades foram surgindo e eu resolvi ir mudando o meu perfil. Acaba que a enfermeira deixa um pouco o lado assistencial e passa para o administrativo (G1).

Eu me formei na Universidade Católica e já trabalhei no [...] na área Clínica [...], depois, parei um tempo, porque eu tive filhos. Aí eu vim para cá para $o[\ldots]\left(\mathrm{G}_{5}\right)$.

Eu fui acadêmica durante muito tempo! $\varepsilon$ me formei totalmente lá, foi a minha primeira experiência de hospital e foi dentro do CTI. Então eu não sei trabalhar em unidade, não sei nem onde que fica, nem, como fica! Eu seria uma péssima profissional fora do CTI. Eu me formei absolutamente dentro do CTI e vim pra cá (G6).

Também se observou entre as entrevistadas o desenvolvimento de seu percurso profissional na própria organização em que atuam como gerentes, o que reflete sua identificação com a organização:

Eu trabalhei em vários hospitais, inclusive aqui. Depois que eu me formei eu fui embora, trabalhei em São Paulo, trabalhei na saúde pública e depois voltei para a área hospitalar. Depois voltei para Belo Horizonte, fui para um hospital filantrópico e agora estou aqui. Mas foi aqui que eu entrei na área administrativa $(\mathrm{G} 1)$.

Meu percurso nessa área basicamente foi aqui. Tenho dez anos [...] de [...] comecei aqui nessa instituição, passei em outras, mas eu nunca saí daqui não. Sempre tentei conciliar o [...] com outras instituições. Eu me identifico com a empresa e com a instituição, gosto do que eu faço e já estou no Centro Cirúrgico há 5 anos no cargo de coordenação $\left(\mathrm{G}_{2}\right)$.

Como profissional eu acho que caminha da mesma forma; Eu adorava trabalhar aqui na CCIH e tal, mas falei: não, não vou mais ficar só nisso! A CCIH é muito bom, você aprende muito, mas você fica assim, é... vocêfaz muito e quem aparece éo médico. Então eu falei: não, não é isso que eu quero, acho que eu vou correr atrás de outra coisa, e por aí foi e então eu fui para a gerência (G9).
A entrevistada refere-se ao papel gerencial como algo que permite à enfermeira maior visibilidade na organização e o exercício das atividades com maior grau de autonomia. Também é interessante observar a importância atribuída pelas gerentes ao contato anterior com a organização, o que permite maior conhecimento do contexto dos hospitais e identificação com a cultura dos mesmos, facilitando o exercício das práticas gerenciais. Nessa perspectiva, Dubar (1997) destaca a importância do sentimento de pertença do trabalhador com a organização na qual desenvolve suas práticas profissionais, estando esse sentimento diretamente ligado ao reconhecimento profissional e social.

A valorização da experiência profissional foi manifestada pelas gerentes por meio da ênfase atribuída ao tempo de exercício profissional, o que é exposto espontaneamente ao se apresentarem:

Eu sempre fui enfermeira assistencial, eu já tenho 19 anos de Enfermagem (G1).

Bom, meu nome é [...], sou enfermeira. Tenho dezanos de formada $\left(\mathrm{G}_{2}\right)$.

Eu sou [...], enfermeira, formada há 16 anos pela $P U C\left(\mathrm{G}_{3}\right)$.

Eu sou [...], eu tenho dez anos de formada, formeina Universidade Católica (G5).

Hoje eu tenho o aval para isso, né? Porque já tem muito tempo [15 anos] que eu estou aqui no setor (G6).

O tempo na organização ou no próprio setor em que atuam é apontado como um fator que credencia a enfermeira para a realização de suas atividades, conferindo-lhes maior autonomia e poder de decisão. A situação descrita está ligada ao conhecimento técnico das gerentes que, associado aos aspectos conceituais e relacionais, se consolidam como uma competência fundamental para o exercício da gerência.

Assim, a permanência em atividades ligadas à prestação da assistência direta ao paciente em setores fechados (CTI e Bloco Cirúrgico) reforça as particularidades das práticas gerenciais de acordo com o local onde são realizadas. A despeito do tempo na organização e da segurança adquirida durante o percurso profissional, as questões relacionais, bem como ambigüidades vivenciadas pelas gerentes na tentativa de conciliação entre a assistência e a gerência, são apontadas: 
Eu sempre fui uma enfermeira assistencial e de repente as oportunidades foram surgindo e eu resolvi ir mudando o meu perfil. Acaba que a enfermeira deixa um pouco o lado assistencial e passa para o administrativo, e acaba que você se divide, né? Porque não tem jeito! Eu tenho formação e quando eu viro para o lado administrativo, quando eu tenho alguma demanda, acabo fazendo o assistencial, então você fica partida. Então a questão profissional eu acho que é muito por aí. Você acaba que não fica realmente assim: $E$ u sou $100 \%$ administrativo. Então, no Bloco Cirúrgico, muitas vezes a própria demanda do setor te leva à questão assistencial: relacionar-se com o paciente, relacionar-se com a família e tudo, então acaba que você entra na dança também e assiste o paciente, assiste todo mundo e fica com os dois lados. Mas eu acho que isso aí é altamente positivo, cada vez que você aprende e tende para uma mudança o crescimento sem dúvida nenhuma vem $(\mathrm{G} 1)$.

Por outro lado, a gerente expressa positivamente a ligação estabelecida entre a assistência e a gerência, refletindo seu amadurecimento profissional e a possibilidade de uma interface entre as duas dimensões do cuidado.

Eu sempre gostei do lado de doente mesmo, do paciente. $E$ sempre fiz duas coisas: coordenar e ser enfermeira. Mas eu sempre me perdi nessa questão porque a gente nunca sabe o que é essa questão de coordenar... Pelo menos eu, é meio difícil para mim, porque eu sempre gostei desse lado de paciente, mas eu sempre fiz tudo, sempre dei conta [...] E hoje eu acho que eu estou sentindo mais frustrada porque eu não olho mais as coisas de paciente, parece que eu estou mais parada, parece que eu não estou sabendo mais fazer as coisas, parece que eu esqueci a Enfermagem! Entendeu? Porque esse lado meu, esse outro de paciente é mais aguçado. Eu acho às vezes que eu não estou servindo mais para a coisa [cargo de gerente] ( $\left.\mathrm{G}_{7}\right)$.

Algumas gerentes explicitam as dificuldades em conviver com os papéis assistenciais e gerenciais, o que pode ser explicado, entre outros fatores, pela recente profissionalização da gerência no setor hospitalar. Assim, verifica-se a fase de transição que tem sido vivenciada pelos gerentes de uma forma genera- lizada. Considerando a importância do espaço do trabalho na configuração identitária do trabalhador e, principalmente, do gerente, há que se destacar a existência de uma identidade em transição, ou conforme sugerem Ciampa (2001) e Jacques (2001), uma identidade em "metamorfose", influenciada por questões mais abrangentes e complexas, como as relações de poder, de gênero e a cultura que permeia a organização hospitalar.

O conflito que perpassa a vivência de algumas das gerentes em relação às atividades administrativas e assistenciais pode ser exemplificado por meio do seguinte trecho de discurso apresentado pela G1, ao falar sobre as mudanças ocorridas após ter assumido o cargo gerencial:

Bom, eu acho que resposta disso aí é o que meu filho sempre fala pra mim (riso), ele fala assim: 'você deixou de ser enfermeira!' (riso) então eu acho que é bem isso! Você passa a ter o seu foco voltado para as questões administrativas, para o dia-a-dia, para a burocracia, para essas questões de conta, auditoria, entendeu? Antes a gente tinha esse foco no assistencial. O foco administrativo te consome, né? A questão administrativa passa a ser a sua profissão e a sua formação deixa de existir. Mesmo que na realidade isso não aconteça. Mas o que passa para as outras pessoas é que você deixou de ser enfermeira, você não é enfermeira mais (G1).

O depoimento reflete a crise de identidade vivenciada pela gerente, a qual afirma ter "deixado de ser enfermeira" para se transformar em "administradora”. Assim, gerência e assistência se configuram como fazeres distintos, não podendo ser exercidos ao mesmo tempo pela mesma pessoa, sendo necessário migrar de um papel para o outro. No entanto, G1 demonstra não ter conseguido concretizar essa "passagem migratória" e, portanto, vivencia de forma conflitante a função gerencial.

Ainda em relação ao trecho de entrevista apresentado, verifica-se a manifestação da identidade virtual da enfermeira por meio da visão de seu filho adolescente. Essa identidade é associada às práticas assistenciais, sendo reforçada pela própria entrevistada ao endossar o posicionamento de seu filho, e culmina com uma vivência profissional conflitante e, por vezes, sofrida por parte da gerente. Em outras palavras, 
percebe-se que a entrevistada não consegue romper com as práticas assistenciais e, por isso, vivencia uma crise de identidade. A esse respeito, é oportuno chamar a atenção para o fato de a identidade configurarse como um fenômeno processual e dinâmico, não podendo, portanto, ser detida de forma completa e definitiva. Dessa forma, a identidade exige tempo de construção e de amadurecimento e, no caso específico das gerentes pesquisadas, sua vivência em cargos gerenciais está associada aos processos de reestruturação nos hospitais, os quais, por sua vez, são relativamente recentes.

A envolver-se nas práticas gerenciais, a enfermeira amplia seu leque de responsabilidades com a organização. Assim, em algumas situações, é levada a se afastar de suas atividades técnico-profissionais específicas, as quais se tornam secundárias. No caso estudado, percebe-se que algumas das entrevistadas, apesar de manterem uma relação identitária forte com o "ser enfermeira" e, portanto, identificando-se como tal, conseguem deslocar-se das atividades assistenciais para se dedicarem, prioritariamente, à gerência, ainda que, em algumas situações, isso implique conflitos pessoais e profissionais, podendo interferir em seu desempenho profissional. O interessante é que, ainda que as gerentes se aproximem dos conteúdos de administração na graduação e façam especialização na área gerencial, sua “alma” de enfermeira é preservada, mantendo-se viva, forte, atuante e resistente.

A permanência da gerente em atividades assistenciais apresenta-se de forma diferenciada quando focamos a análise nos setores fechados e abertos dos hospitais pesquisados. Significa dizer que, nos CTI e Blocos Cirúrgicos, as práticas gerenciais da enfermeira assumem uma conformação diferenciada quando comparadas às Unidades de Internação. Assim, nos setores fechados, a atividade assistencial desenvolvida pela gerente é considerada como parte da ação gerencial e seu envolvimento em atividades dessa natureza constitui uma estratégia de fortalecimento das relações interpessoais. Por outro lado, ao descreverem suas práticas nas unidades de internação, as gerentes assumem seu distanciamento das questões assistenciais, sem que isso represente para elas algum tipo de conflito.

No plano organizacional, os traços identitários encontravam-se, fundamentalmente, ligados à identi- ficação das gerentes com a organização, cabendo ressaltar que a identificação é descrita como a aproximação da realidade objetiva (própria da organização) e subjetiva (própria do indivíduo) e sustentada em bases anteriores de socialização. Assim, o processo de identificação trabalhador/organização passa pelo desenvolvimento e envolvimento dos atores num conjunto de práticas ideológicas, anteriores à sua inserção no mercado de trabalho, capacitando-o a reproduzir determinadas posturas apreendidas durante a vida (Goffman, 1985). Conforme assinala Pagès e colaboradores (1987), a identificação do indivíduo com a organização é estabelecida por meio de laços materiais e morais, vantagens econômicas, satisfações ideológicas e laços psicológicos, tornando-a (a organização) fonte de angústia e de prazer para os profissionais envolvidos em seus processos de produção. No caso das gerentes entrevistadas, observou-se que sua identificação com a organização está associada, entre outros aspectos, aos laços ideológicos e afetivos, conforme detalhado a seguir.

Comecei aqui nessa instituição. Passei em outras, mas eu nunca saí daqui não. Sempre tentei conciliar o [...] com outras instituições. Me identifico com a empresa e com a instituição. Gosto do que eu faço $\left(\mathrm{G}_{2}\right)$.

Meu primeiro emprego foi aqui e estou aqui até hoje, graças a Deus $\left(\mathrm{G}_{7}\right)$.

Eu não tenho, aliás, eu acho que nunca tive essa mentalidade de ir hoje daqui para um outro hospital, por que eu acho os problemas só mudam de endereço. Na realidade, se eu tenho uma estrutura aqui, eu trabalho aqui e vou estar trabalhando para que as coisas melhorem aqui. Sem ficar pensando: será que outro lugar é melhor? Nem penso nisso, porque eu me encontro satisfeita aqui (G6).

Por meio dos depoimentos apresentados, pode-se observar o sentimento de pertença à organização manifestado pelas gerentes. Esse sentimento é de fundamental importância no exercício das práticas gerenciais, pois o exercício da gerência significa representar a organização. Conhecendo e compartilhado os valores, as crenças e a cultura da organização, a enfermeira assume a condução da equipe de saúde e o alcance das metas organizacionais. Nessa perspectiva, percebe- 
se a existência de laços de identificação ideológicos e psicológicos com a organização. Os primeiros abrangem os princípios, políticas, diretrizes, valores e crenças repassados pela organização, tendo um caráter legitimador das ações organizacionais, e os segundos são criados em função da imagem de força e de poder propostas aos indivíduos pela organização (Pagès, e col., 1987).

No plano individual, os traços identitários expressos pelas gerentes também foram evidenciados. Assim sendo, as gerentes foram enfáticas ao trazer à tona alguns aspectos relevantes de sua vida privada e profissional, assim como a manifestação de uma autoimagem positiva.

Quanto às questões relativas à vida privada, as gerentes mencionam questões próprias do espaço doméstico, principalmente os filhos e as dificuldades em conciliar o trabalho e a vida privada, o que nos remete a refletir acerca das questões de gênero e sobre suas implicações no mundo feminino.

Em termos do perfil das gerentes pesquisadas, verificou-se que, do total de nove gerentes, duas eram solteiras, seis eram casadas oficialmente e uma vivia há três anos com o companheiro. Há que se chamar a atenção para as particularidades que permeiam a vida da mulher trabalhadora, em suas múltiplas dimensões, independentemente de sua ocupação no mundo do trabalho. No caso das enfermeiras-gerente, durante sua apresentação vêm à tona aspectos referentes à sua vida privada e às dificuldades vivenciadas na conciliação do espaço do trabalho e doméstico. Essa situação reflete as diferenças que marcam o universo masculino e feminino, a despeito dos avanços ocorridos na sociedade.

Eu sou uma pessoa tranqüila. Eu sou casada, eu tenho dois filhos já moços. Não tenho nada que descoordene a minha questão de vida pessoal não. Vivo bem, tranqüila, tenho uma vida tranqüila, vivo bem com o meu marido, com meus filhos e tal (G1).

Com base no trecho de entrevista apresentado, infere-se que a "não-descoordenaçao" da vida privada da entrevistada está ligada à faixa etária de seus filhos, tendo em vista que, na seqüência de entrevista, ao comentar sobre os impactos da função gerencial em sua vida pessoal e familiar, a mesma gerente faz a seguinte afirmação:
O impacto maior que teve foi no meu tempo. Eu fico muito mais tempo dentro do hospital do que quando eu era da área assistencial e com isso eu dispenso menos tempo a minha família. Eu me sinto mais consumida pelo hospital. Porque você passa a trabalhar uma carga horária maior, passa a ter uma quantidade de responsabilidades maior, e você passa a ter menos tempo para resolver as suas questões pessoais lá fora. Então eu acho que é justamente aí que pega, e que fica complicada a questão [...] isso é um problema, porque aí você tem a questão da sua família relegada ao segundo plano. Então o hospital passa a te consumir um tempo maior, uma atenção maior porque tudo que acontece nas 24 horas do dia évocê que é acionada, então essa questão é muito complicada, porque a sua vida passa a ser limitada, e isso é difícil. Porque as suas outras questões não deixam de existir, continuam existindo. Então você acaba não conseguindo destinar aquele tempo que você tinha para o filho, para o marido, para a família como um todo, então é muito difícil! (G1)

Também são perceptíveis as maiores cargas de responsabilidade e a sobrecarga de trabalho advindo da função gerencial e seus reflexos no espaço privado. Além disso, a entrevistada parece expressar certo desconforto em ocupar o cargo de gerente. No entanto, conforme nos traz Sainsaulieu (1997), o aumento da responsabilidade e, por conseguinte, da carga de trabalho dos profissionais no novo contexto das organizações constitui uma característica própria desse cenário. Assim, a sobrecarga apontada pelas gerentes parece estar relacionada a um processo natural e inerente às organizações, senão a uma situação particular por ela vivenciada.

A dificuldade encontrada na conciliação dos papéis profissionais e domésticos das gerentes também foi identificada:

Eu sou casada, tenho dois filhos. Então eu sei que tem hora que é difícil conciliar a vida pessoal com a profissional, principalmente por causa dessas características (características do setor no qual atua), cargo de coordenação! Então tem hora realmente que vocêtem vontade assim: "ah, não, cansei", mas aí você pára pra pensar e vai colocar na balança: não, acho que ainda dou conta de mais! (G2) 
O depoimento da entrevistada fornece indícios da visão introjetada da enfermeira acerca da necessidade de "dar conta de tudo" (Daher, 200o; Lima Júnior, 1998). Essa situação está ligada aos laços de identificação das gerentes com a organização, os quais são expressos por meio de sua máxima "doação" profissional.

Além da sobrecarga de trabalho vivenciada pelas gerentes ao se referirem aos seus projetos de vida futuros, também se percebe a intenção de realizar um projeto de vida diferente, no qual estão presentes investimentos em uma melhor qualidade de vida, disponibilidade de tempo para desenvolver projetos pessoais:

Olha, eu pretendo ainda, continuar fazendo o que eu faço. Eu não sei por quanto tempo, mas eu pretendo é... daqui a alguns anos, também não posso te falar quantos, ter uma qualidade de vida diferente da que eu tenho, pra melhor [...] eu não acho a minha qualidade de vida ruim, mas diferente em função de... ter outras atividades é... pessoais. Talvez daqui a alguns anos, eu não exerça essa função direta, talvez alguma assessoria, uma consultoria, cargos até de uma responsabilidade menor, para que eu possa dedicar um pouco de tempo para outros planos pessoais $\left(\mathrm{G}_{3}\right)$.

Os projetos de vida das gerentes são influenciados pelo fato de serem mulheres, o que pode ser analisado sob a ótica do "fenômeno do teto de vidro", descrito por Steil (1997), o qual consiste na limitação do acesso feminino a determinados espaços, por meio de barreiras sutis, mas suficientemente fortes. No caso específico das gerentes pesquisadas, verificou-se que essas barreiras ou empecilhos estão presentes tanto na esfera profissional quanto na privada, tendo em vista que parte das dificuldades por elas enfrentadas estão relacionadas à suas atribuições no espaço doméstico, com ênfase para aquelas voltadas para o cuidado com os filhos.

Ainda no que concerne ao plano individual, identificou-se a presença de uma auto-imagem positiva expressa pelas gerentes. A esse respeito, salienta-se que um dos principais fundamentos da teoria da identidade social postula a necessidade humana de preservação de elevado grau de auto-estima (Steil, 1997; Dubar, 1997; Sainsaulieu, 1997). Assim, observou-se que, ao se apresentarem, as gerentes expressaram seu senti- mento em relação à sua percepção sobre sua auto-imagem, tendo se destacado a percepção positiva sobre si próprias e sua determinação em alcançar seus propósitos de vida, ainda que não fossem apoiadas por outras pessoas.

Tomando como base os traços identitários das gerentes entrevistadas e considerando os planos profissional, organizacional e pessoal, evidenciou-se uma relativa coerência de atitudes, de representações e de condutas entre as gerentes pesquisadas, o que, na visão de Abboud, 1968, citado por Dubar (1997, p. 196), representa "uma ótica global do trabalho, da vida profissional e da vida social no interior de um mesmo horizonte profissional". Emergem, assim, algumas características do conceito de identidade social, isto é, uma identidade marcada por certa linearidade no percurso profissional das gerentes, principalmente se considerarmos que seu ingresso na carreira gerencial se dá por meio de atividades assistenciais. Nesse percurso, a enfermeira assume funções ligadas à gerência, sendo oportuno chamar a atenção para o fato de a enfermeira, diferentemente do profissional médico, (Barbosa, 1996) possuir formação, ainda que básica, em administração, a qual possibilita assumir o papel gerencial em conformidade com as atuais demandas dos hospitais.

Acrescenta-se, ainda, que a migração para o papel gerencial é produto da valorização da competência profissional da enfermeira, a qual possui habilidades e conhecimentos que lhe possibilitam o exercício da função. No caso das gerentes pesquisadas, percebese que apresentam uma interiorização do sucesso profissional e de valorização pessoal.

\section{Considerações Finais}

Em face dos imperativos ambientais e organizacionais, a enfermeira vem ocupando cada vez mais espaço na gestão hospitalar, seja na gestão de unidades operativas ou assumindo cargos administrativos que exigem uma visão ampliada do funcionamento geral da organização, com destaque para o conhecimento em gestão de pessoas, de recursos financeiros, materiais e tecnológicos. Dessa forma, observa-se uma inserção cada vez maior de enfermeiras em postos administrativos, especialmente em cargos de natureza ge- 
rencial, nos níveis estratégico e intermediário das organizações.

Mediante o esforço analítico deste estudo, evidenciou-se que os hospitais privados envolvidos na investigação vêm passando por intensas transformações estruturais, gerenciais e processuais e constituem espaços fundamentais na configuração identitária da enfermeira-gerente. Essa importância está ligada ao fato de as organizações hospitalares serem marcadas por intensas e complexas relações sociais que, por sua vez, são vivenciadas de formas diversas pelos atores envolvidos em seus processos produtivos. Salienta-se, ainda, a ampliação do espaço de trabalho da enfermeira e a incorporação de instrumentos norteadores de suas práticas gerenciais.

O cotidiano de trabalho da enfermeira-gerente caracterizou-se pela realização de atividades assistenciais e gerenciais, com algumas distinções entre os setores abertos (Unidades de Internação e o hospital como um todo) e fechados (CTI e Bloco cirúrgico) pesquisados, tanto no que se refere às atividades propriamente ditas quanto em relação ao sentimento das gerentes no exercício dessas atividades. A multiplicidade de tarefas e a ausência de uma rotina de trabalho também foram mencionadas, estando ligadas à fase de reestruturação pela qual vêm passando as organizações estudadas.

A identidade social real da enfermeira-gerente foi apreendida por meio da análise de seus traços identitários e de sua identidade biográfica e relacional, na qual foram analisadas questões relativas ao seu reconhecimento e às experiências relacionais de gênero. Os traços identitários foram expressos nos níveis profissional, organizacional e individual. No plano profissional, verificaram-se, junto às gerentes pesquisadas, a preservação e reforço da identidade social da enfermeira, a trajetória profissional como uma evolução da prática assistencial para a gerencial, a valorização da experiência prática e sua permanência em atividades ligadas à prestação da assistência direta ao paciente.

No plano organizacional, foi expresso o sentimento de identificação com a organização e, no plano individual, foram explicitadas questões ligadas à vida privada e à auto-imagem positiva das gerentes. No que concerne aos traços identitários descritos, ressalta-se que a migração do papel assistencial para o papel gerencial surge como resultado da valorização da competência profissional da enfermeira-gerente e reflete a interiorização do seu êxito profissional e do sentimento de auto-valorização. Ademais, as gerentes compartilham uma identidade situada na concepção intelectual, a qual se sustenta na sua formação profissional e no processo informal de aprendizagem na área assistencial. Dessa forma, é reforçada a importância da qualificação profissional na dinâmica identitária e, portanto, na identidade social e profissional da enfermeira.

Tendo em vista os resultados obtidos neste estudo, percebe-se a tendência cada vez mais marcante de configuração da gestão hospitalar como um campo diferenciado de investigação e a necessidade de incorporação da gerência como uma prática profissional distinta. Ademais, as identidades sociais e profissionais são resultados de construções sociais alicerçadas nas trajetórias individuais, nos processos de formação e nas relações de trabalho. Refletem, portanto, configurações identitárias específicas do momento histórico e de produção de cada sociedade. Dessa forma, salienta-se a natureza contingencial e dinâmica da identidade, o que a caracteriza como um "eterno vir a ser”. Neste estudo, foram destacados traços identitários referentes às enfermeiras-gerente de hospitais privados de grande e médio porte de Belo Horizonte, o que restringe sua validade aos dados empíricos nos quais se apoiaram, sendo pertinente e enriquecedor do ponto de vista prático e teórico a realização de novos estudos que possam vir a complementar ou alargar as bases aqui construídas.

Nessa ótica, considera-se pertinente a realização de novas investigações em Organizações de Saúde de natureza e porte diferentes, tendo em vista sua heterogeneidade cultural e histórica. Também são relevantes outros estudos que envolvam diferentes categorias profissionais, haja vista a complementaridade do trabalho na Saúde e as intensas relações de poder que caracterizam os hospitais, os quais não representam somente organizações ou meios de trabalho, mas, sobretudo, uma possibilidade de construção individual e coletiva. 


\section{Referências}

ALVES, M. Causas do absenteísmo na enfermagem: uma dimensão do sofrimento no trabalho. 1996. Tese (Doutorado em Enfermagem) - Escola de Enfermagem, Universidade de São Paulo, São Paulo, 1996.

ALVES, M.; BRITO, M. J. M. Gerentes dos serviços públicos de saúde: um estudo descritivo do estado de Minas Gerais. Belo Horizonte: Escola de Enfermagem da UFMG, 2001. Relatório.

BARBOSA, P. R. A profissionalização do dirigente hospitalar público como condição para melhores performances gerenciais. Saúde em Debate, Londrina, v. 52, p. 24-34, set. 1996.

BARDIN, L. Análise de conteúdo. Lisboa: Ed. 70, 1977.

BARROS, S. M. P. F. Gerenciamento em saúde: implicações, tendências e perspectivas para a enfermagem. In: CONGRESSO BRASILEIRO DE ENFERMAGEM, 45., 1993, Recife. Anais... Recife: Ed. Universitária da UFPE, 1994. p. 93-103.

BOCCHI, S. C. M.; FÁVERO, N. Caracterização das atividades diárias do enfermeiro chefe de seção em um hospital universitário. Revista Latino-Americana de Enfermagem, Ribeirão Preto, v. 4, n. 2, p. 41-59, jul. 1996.

BRITO, M. J. M. O enfermeiro na função gerencial: desafios e perspectivas na sociedade contemporânea. 1998. Dissertação (Mestrado em Enfermagem) - Escola de Enfermagem da UFMG, Belo Horizonte, 1998.

BRITO, M. J. M.; MELO, M. C. O. L. Influência de ações de reestruturação produtiva na atividade gerencial de enfermeiras em hospitais da rede privada de Belo Horizonte. Belo Horizonte: Núcleo de Relações de Trabalho e Tecnologias de Gestão, 2001a. Relatório.

BRITO, M. J. M.; MELO, M. C. O. L. A identificação da enfermeira-gerente com a organização em que trabalham: o caso de um hospital filantrópico de Belo Horizonte. Revista Mineira de Enfermagem, Belo Horizonte, v. 5, n. 1/2, p. 44-51, jan./dez. 20o1b.
BRITO, M. J. M.; MONTEIRO, P. R; COSTA, J. O. Interface da mudança e dos modos de gestão na rede hospitalar privada de Belo Horizonte: caminhos e desencontros na ótica da gerente-enfermeira. In: ENANPAD - ENCONTRO NACIONAL DA ASSOCIAÇÃO DOS PROGRAMAS DE PÓS-GRADUAÇÃO EM ADMINISTRAÇÃO, 16., 2002, Salvador. Anais... Salvador: Anpad, 2002. p. 297.

CALDAS, M. P.; WOOD JR, T. Identidade organizacional. Revista de Administração de Empresas, São Paulo, v. 37, n. 1, p. 6-17, 1997.

CASTELLS, M. O poder da identidade. 2. ed. São Paulo: Paz e Terra, 20oo.v. 2.

CECÍLIO, L. C. O. Modernização gerencial dos hospitais públicos: o difícil exercício da mudança.

Revista de Administração de Empresas, Rio de Janeiro, v. 31, n. 3, p. 36-47, maio/jun. 1997.

CIAMPA, A. da C. Identidade. In: LANE, S. T. M.; CODO, W. (Org.). Psicologia social: o homem em movimento. 13. ed. São Paulo: Brasiliense, 2001. p. 58-75.

DAHER, D. V. Por detrás da chama da lâmpada: a identidade social do enfermeiro. Niterói: Ed. UFE, 2000.

DUBAR, C. A socialização-construção das identidades sociais e profissionais. 2 ed. Porto: Porto Ed., 1997.

GOFFMAN, E. A representação do eu na vida cotidiana. Petrópolis: Vozes, 1985.

HALL, S. A identidade na pós-modernidade. 3. ed. Rio de Janeiro: DP\&A, 1999.

JACQUES, M. da G. Identidade. In: JACQUES, M da G. et al. Psicologia social contemporânea. 5. ed.

Petrópolis: Vozes, 2001. p. 159-167.

KRON, T.; GRAY, A. Administração dos cuidados de enfermagem ao paciente: colocando em ação as habilidades de liderança. Rio de Janeiro: Interlivros, 1994 .

LIMA JÚNIOR, J. H. V. Trabalhador de enfermagem: de anjo de branco a profissional. 1998. Tese - Escola de Administração de Empresas de São Paulo, Fundação Getúlio Vargas, São Paulo, 1998. 
MELO, M. C. de O. L. A gerência feminina em setores industrial e bancário: o conservadorismo internalizado versus o moderno em construção. In: THIRD INTERNATIONAL CONFERENCE OF THE IBEROAMERICAN ACADEMY OF MANAGEMENT, 2002, Porto Alegre. Anais ... São Paulo: CLADEA, 2002 p. 37 .

MELO, M. C. de O. L. Gênero e poder em organizações do setor bancário: habilidades diferenciadas e desafios específicos da gerência feminina. In: COLÓQUIO INTERNACIONAL SOBRE O PODER LOCAL, 9.; COLÓQUIO INTERNACIONAL EL ANÁLISIS DE LAS ORGANIZACIONES Y LA GESTION ESTRATÉGICA - PERSPECTIVAS LATINAS, 2., 2003, Salvador. Anais... Salvador, 2003. p. 21-29.

NKOMO, S. M.; COX JR, T. Diversidade e identidade nas organizações. In: FACHIN, R.; FISCHER T. (Org.). Handbook de estudos organizacionais: modelos de análise e novas questões em estudos organizacionais. São Paulo: Atlas, 1999. v. 1, p. 334360.

PAGÈS, M. et al. O poder das organizações: a dominação das multinacionais sobre os indivíduos. São Paulo: Atlas, 1987.

SAINSAULIEU, R. L'identité ou travail. 2 éd. Paris: Presses da la Foundation Nationale des Sciences Politiques, 1985 .
SAINSAULIEU, R. Sociologia da empresa: organização, cultura e desenvolvimento. Lisboa: Instituto Piaget, 1997.

STEIL, A. V. Organizações, gênero e posição hierárquica: compreendendo o fenômeno do teto de vidro. Revista de Administração, São Paulo, v. 32, n. 3, p. 62-69, jul./set. 1997.

TAJFEL, H. M. Differentiation between social groups: studies in the social psicology of intergroup relations, european monographs in social psychology. London: Academic Press, 1978.

TURATO, E. R. Tratado de metodologia da pesquisa clínico-qualitativa: construção teóricoepistemológica, discussão comparada e aplicação nas áreas de saúde e humanas. Petrópolis: Vozes, 2003.

TREVISAN, M. A. Enfermagem hospitalar: administração e burocracia. Brasília, DF: Universidade de Brasília: 1988.

WALDOW, V. R. A opressão na enfermagem: um estudo exploratório. In: LOPES, M. J. M.; MEYER, D. E.; WALDOW, R. V. (Org.). Gênero e saúde. Porto Alegre: Artes Médicas, 1996. p. 106-132.

YIN, R. K. Estudo de caso: planejamento e métodos. 2. ed. Porto Alegre: Bookman, 2001. 